\title{
RESEARCH
}

\section{Predictors of inappropriate antibiotic prescribing among primary care physicians}

\author{
Genevieve Cadieux MSc, Robyn Tamblyn PhD, Dale Dauphinee MD, Michael Libman MD
}

$\infty \quad$ See related article page 895

\section{ABSTRACT}

Background: Inappropriate use of antibiotics promotes antibiotic resistance. Little is known about physician characteristics that may be associated with inappropriate antibiotic prescribing. Our objective was to assess whether physician knowledge, time in practice, place of training and practice volume explain the differences in antibiotic prescribing among physicians.

Methods: A historical cohort of 852 primary care physicians in Quebec who became certified between 1990 and 1993 was followed for their first 6-9 years of practice (1990-1998). We evaluated whether inappropriate antibiotic prescribing had occurred during the study period (1990-1998) for viral (prescription of antibiotics) and bacterial (prescription of second- or third-line antibiotics given orally) infections. We used logistic regression to estimate the independent contributions of time in practice, practice volume, place of medical training and scores on licensure examinations. Physician sex and visit setting were controlled for, as were patient age, sex, education, income and geographic area of residence.

Results: A total of 104230 patients who received a diagnosis of a viral infection and 65304 who received a diagnosis of a bacterial infection were included in our study. International medical graduates were more likely than University of Montréal graduates to prescribe antibiotics for viral respiratory infections (risk ratio [RR] 1.78, 95\% confidence interval [Cl] 1.30-2.44). Inappropriate antibiotic prescribing increased with time in practice. Physicians with a high practice volume were more likely than those with low practice volume to prescribe antibiotics for viral respiratory infections (RR 1.27, 95\% $\mathrm{Cl}$ 1.09-1.48) and to prescribe second- and third-line antibiotics as first-line treatment (RR $1.20,95 \% \mathrm{Cl}$ 1.06-1.37). Physician scores on licensure examinations were not predictive of inappropriate antibiotic prescribing.

Interpretation: International medical graduates, physicians with high-volume practices and those who were in practice longer were more likely to prescribe antibiotics inappropriately. Developing effective interventions will require increased knowledge of the mechanisms that underlie these predictors of inappropriate antibiotic prescribing.

Une version française de ce résumé est disponible à l'adresse www.cmaj.ca/cgi/content/full/I77/8/877/DCI

$C M A J$ 2007;177(8):877-83
I nappropriate antibiotic use is an important problem worldwide. Both the use of antibiotics for the treatment of viral respiratory infections ${ }^{1,2}$ and the overuse of broad-spectrum antibiotics to treat bacterial infections ${ }^{3,4}$ promote antibiotic resistance, ${ }^{5,6}$ increase the likelihood of preventable drug-related adverse events ${ }^{7}$ and increase the use and cost of health care services. ${ }^{8}$ Despite considerable efforts to identify patient characteristics that predict inappropriate antibiotic prescribing, there is no conclusive evidence that patient expectations, frequency of health care use, sex, age or clinical presentation increase the likelihood of inappropriate antibiotic prescribing. However, few studies have investigated physician characteristics associated with antibiotic prescribing, even though the rate of antibiotic prescribing has been reported to vary greatly among physicians. ${ }^{9,10}$

Four hypotheses have emerged to explain the differences in antibiotic prescribing among physicians. The first hypothesis is that there is a lack of physician knowledge. In support of this hypothesis, international medical graduates generally score lower than Canadian and US graduates on licensing examinations. ${ }^{11}$ International medical graduates also issue more antibiotic prescriptions than their British ${ }^{12}$ and North American ${ }^{13}$ counterparts. The second hypothesis is that practice experience (time in practice) is responsible for the differences in antibiotic prescribing. Cross-sectional studies have reported that attending staff physicians, compared to interns and residents, and older physicians are more likely to prescribe antbiotics inappropriately. ${ }^{14,15}$ Increased antibiotic prescribing over time may also be due to physician "softening" to patient demand for antibiotics ${ }^{16}$ or due to pharmaceutical detailing. The third hypothesis suggests that physician training environment, possibly through professional tradition, cultural expectations or pharmaceutical detailing, is responsible for differences in antibiotic prescribing among physicians. For example, regional variation in antibiotic prescribing in European countries has been documented. ${ }^{17,18}$ The fourth hypothesis is that inappropriate antibiotic prescribing is the result of the avoidance of timeconsuming patient education. ${ }^{16}$ In support of this hypothesis, physicians with higher practice volumes are more likely to prescribe antibiotics inappropriately. ${ }^{19,20}$

From the Department of Epidemiology and Biostatistics (Cadieux, Tamblyn) and the Department of Medicine (Tamblyn, Dauphinee), McGill University, and the Division of Infectious Diseases and Department of Medical Microbiology (Libman), Montréal General Hospital, Montréal, Que. 
To date, most studies that have assessed the effect of time in practice on antibiotic prescribing have been crosssectional, and there has been no reliable measure of physician knowledge and diagnostic ability or means of distinguishing training environment from knowledge. Our objective was to identify predictors of inappropriate antibiotic prescribing among primary care physicians. More specifically, we sought to assess whether physician knowledge, time in practice, training environment and practice volume are predictors of inappropriate antibiotic prescribing.

\section{Methods}

\section{Design and study population}

We used a historical cohort design to assess the antibiotic prescribing pattern of physicians who became licensed in Quebec between 1990 and 1993 . We included physicians who were remunerated on a fee-for-service basis. We excluded salaried physicians because there was no accurate way to identify all of their patients.

We included patients who were seen by a study physician from 1990 to 1998 and who were covered by the Quebec provincial insurance plan and by the provincial prescription drug insurance plan (people receiving employment assistance, people aged 65 years or more, and since 1996 , all permanent residents not insured through their employer). We excluded people with private insurance because there was no accurate way to determine what antibiotics had been prescribed.

We identified all episodes of viral respiratory infections and bacterial respiratory and urinary tract infections that were diagnosed by study physicians from 1990 to 1998 from the physician billing claims database. The International Classification of Diseases (ninth revision [ICD-g]) codes used are listed in Appendix I (available online at www.cmaj.ca/cgi/content/full / $177 / 8 / 877 / D_{2}$ ). Viral cultures are seldom performed in community-care settings; thus, our classification of respiratory infections as having a likely viral etiology was based on the diagnosis (i.e., common cold, influenza, viral pneumonia) and on evidence from etiologic and antibiotic treatment studies ${ }^{21,22}$ (i.e., acute laryngitis, unspecified acute upper respiratory tract infection). We excluded episodes that were preceded by a similar infection in the year before diagnosis. We identified diagnoses of chronic obstructive pulmonary disease and HIV/AIDS using a validated method, ${ }^{23}$ and we excluded these patients because of different treatment guidelines.

We performed a validation study to assess the degree of correspondence between the ICD- 9 codes used in the physician billing claims database and the reasons for the visits stated in the patients' medical records. We reviewed the records of 729 patients who had a total of 3526 visits during the study period. The likelihood of a diagnosis in a physician billing claim being the same as the one listed in the patient's medical record (positive predictive value) was 1.00 for acute laryngitis, 0.89 for common cold, 0.66 for influenza, 0.82 for unspecified acute upper respiratory tract infection, 0.87 for pharyngitis, 0.88 for otitis media, 0.90 for sinusitis, 0.72 for acute bronchitis and $0.9 \mathrm{I}$ for community-acquired pneumonia.

This project was reviewed and approved by the Institu- tional Review Board at McGill University and by the Comité d'accès à l'information du Québec.

\section{Data sources}

Primary care physicians who obtained their licence between I 990 and I 993 were identified by the Quebec College of Physicians. The college provided the physicians' licence numbers to the provincial health insurance agency in order to retrieve data on practice activity.

We used 4 Quebec databases (registrant database, physician billing claims database, prescriptions claims database and hospitalization database) to assess inappropriate antibiotic prescribing among study physicians. Each patient's personal lifelong health insurance identifier was used to link the databases, and the linkage rate was Ioo\%. We obtained the patient age, sex, postal code and date of birth from the registrant database. Physician sex was obtained from the Medical Council of Canada. We obtained visit setting, diagnostic code, treating physician and date of service from the physician billing claims database. The antibiotic prescribed, the prescribing physician and the date of dispensation were obtained from the prescriptions claims database. We obtained the discharge diagnoses and the dates of admission to and discharge from hospital from the hospitalization database, which includes data on all people admitted to hospital in Quebec during the study period.

\section{Outcome measures of inappropriate antibiotic prescribing}

We used 2 measures to determine whether inappropriate antibiotic prescribing had occurred. The first measure was inappropriate antibiotic therapy for respiratory infections with a likely viral cause. This was defined as a prescription of an antibiotic to be given orally dispensed within 7 days of a diagnosis of a likely viral respiratory infection. The second measure was prescription of a second- or third-line antibiotic to be given orally dispensed within 7 days of a diagnosis of a new episode of a likely bacterial infection. Classification of antibiotics as first-, second- or third-line was based on published treatment guidelines (Appendix 2, available online at at www.cmaj.ca/cgi /content/full/I77/8/877/DC2). ${ }^{24}$ We defined the appropriate treatment of a likely bacterial infection either as treatment with a first-line antibiotic, or as the absence of antibiotic treatment because a proportion of infections categorized as potentially bacterial are expected to have a viral cause ${ }^{21,22}$ (e.g., $>90 \%$ of cases of acute bronchitis have a viral cause; ${ }^{25}$ thus, no antibiotic treatment is appropriate).

\section{Predictors of inappropriate antibiotic prescribing}

We investigated whether the following physician characteristics are predictors of inappropriate antibiotic prescribing: physicians' overall knowledge and knowledge of infectious diseases; training environment; time in practice; and practice volume.

We used medical licensure examination scores as a measure of the physician's overall knowledge and knowledge of infectious diseases. Physicians must pass the Medical Council of Canada Qualifying Examination for unrestricted licensure in Canada and the Quebec Licensing Examination for licensure as a family physician in Quebec. One of us (G.C.) identified multiple- 
choice questions in part I of the examination that test knowledge of infectious diseases and antibiotic treatment. Of the questions in part $\mathrm{I}$ of the examination, $18 \%-22 \%$ were related to infectious diseases or antibiotics. Intrarater reliability was measured using 25 randomly selected questions that were reviewed twice, and the agreement between the first and second review was $100 \%$. The infectious disease subscore was then computed by the Medical Council of Canada for all physicians who wrote the qualifying examination from Ig88 to I99I, and the raw scores were standardized to adjust for differences in the level of difficulty between examinations. The correlation between the overall score and the infectious disease subscore was $r=0.82$. Scores based on a small number of items are less reliable than those based on a large number of items; thus, we also assessed the relation between inappropriate antibiotic prescribing and overall score.

We obtained from the Quebec College of Physicians each physician's school of undergraduate medical education and year of graduation. The schools were categorized as University of Montréal, Laval University, McGill University and Sherbrooke University. There were too few graduates of medical schools outside Quebec who were practising in Quebec during the study period to examine each school individually; thus, we grouped these physicians either as graduates of other Canadian and US schools, which have a common accreditation framework, or as international medical graduates. Graduates from the University of Montréal were the largest group; thus, these physicians were used as the reference group.

Both time since graduation from medical school and time in practice should influence prescribing; thus, we used time since graduation as a measure of physician experience because it includes time in practice. For each infection episode diagnosed, the number of years that the physician had been in practice was obtained by subtracting the year of graduation from the year in which the infection episode occurred.

We used the physician billing claims database to determine practice volume for each study physician. We defined mean daily practice volume as the mean number of patients seen per physician workday in the calendar year of the infection. A physician workday was defined as a day when the physician saw at least I patient.

\section{Statistical analysis}

We performed multivariable logistic regression analyses for clustered data using generalized estimating equations to estimate the association of physician knowledge, time in practice, training environment and practice volume with inappropriate antibiotic prescribing, while controlling for covariates. The episode of infection was the unit of analysis, and the cluster unit was the study physician. To avoid bias, a single episode of infection per patient was randomly sampled. Assuming that physician prescribing patterns change over time, we chronologically ordered the episodes of infection and used a first-order autoregressive correlation structure of residuals. The highest correlation adjustment estimated was $r=0.09$ for antibiotic prescribing for viral infections and $r=0$. II for the prescribing of second- and third-line antibiotics as first-line treatment of bacterial infections. Results were considered significant at $p<0.05$. A risk ratio [RR] less than I indicates a physician is less likely to prescribe antibiotics inappropriately and a RR greater than I means a physician is more likely to prescribe antibiotics inappropriately.

We included the following covariates in our analyses: physician sex, visit setting and patient age, sex, income, education and geographic area of residence. We obtained ecologic proxies for patient education and income ${ }^{26}$ from census data gathered in I99I and 1996. We approximated patient income using the mean household income in the patient's 6-digit postal code area of residence. The net education level was obtained by subtracting the proportion of patients without a high school diploma from the proportion of patients with a university degree or a postsecondary diploma in the patient's 6-digit postal code area of residence. We classified the patient's geographic area of residence, an indicator of access to care, as urban, intermediate or rural-remote based on their postal code.

To account for differences in health care use among patients, we adjusted for the number of primary care physicians seen and the number of visits to a primary care physician in the year before the infection episode. We used the establishment code on the physician billing claims to categorize the visit setting as a private clinic, a local community health and social service centre (CLSC) or a hospital-based ambulatory care clinic. The establishment code is audited for accuracy by the Régie de l'assurance maladie du Québec because physicians' level of reimbursement is dependent on the type of establishment where the service was provided.

\section{Results}

In total, 944 primary care physicians obtained their licence in Quebec betweem I990 and 1993. Of these, 912 (96.6\%) began

\begin{tabular}{|c|c|}
\hline Characteristic & No. (\%) of physicians* \\
\hline Male & $366(43.0)$ \\
\hline \multicolumn{2}{|l|}{ Undergraduate medical school } \\
\hline Montréal & $301(35.3)$ \\
\hline Laval & $237(27.8)$ \\
\hline McGill & $62 \quad(7.3)$ \\
\hline Sherbrooke & $152(17.8)$ \\
\hline Other Canadian or US medical school & $53(6.2)$ \\
\hline Foreign medical school & $47 \quad(5.5)$ \\
\hline MCCQE overall score, $\uparrow$ mean (SD) & $-0.24(0.90)$ \\
\hline $\begin{array}{l}\text { MCCQE infectious disease and antibiotic } \\
\text { knowledge score, mean (SD) }\end{array}$ & $0.03(0.91)$ \\
\hline QLEx overall score, $†$ mean (SD) & $-0.04(1.06)$ \\
\hline Daily practice volume, $\neq$ mean (SD) & $28.12(9.74)$ \\
\hline
\end{tabular}

Note: MCCQE = Medical Council of Canada Qualifying Examination, $S D=$ standard deviation, QLEX = Quebec Licensing Examination.

*Unless stated otherwise.

†Standardized score (z score)

$\ddagger$ Mean number of patients seen per day worked during the year the event occurred. 
practising during the study period, and 852 (93.4\%) were remunerated on a fee-for-service basis. Of the 852 physicians included in our study, 366 (43.0\%) were male, 47 (5.5\%) were international medical graduates and $726(85.2 \%)$ wrote the Medical Council of Canada Qualifying Examination (not mandatory for licensure in Quebec) (Table I).

During the study period, 4258362 patients were seen by the study physicians. Of these, I 938206 (45.5\%) were covered by the prescription drug insurance plan in Quebec.

In total, we identified 73I 199 episodes of viral respiratory infections diagnosed by study physicians during the study period. Of these, I04 230 episodes were eligible for inclusion in our study (Figure I). The proportion of episodes of viral respiratory infection that were treated with an antibiotic differed significantly across infection sites $(p<0.001)$, ranging from $22 \%$ for laryngitis to $43 \%$ for influenza.

Of the 564669 bacterial respiratory and urinary tract infections diagnosed by study physicians during the study period, 65304 were included in our study (Figure 2). The proportion of episodes treated with second- or third-line antibiotics, compared with no antibiotics or first-line antibiotics, differed significantly across infection sites $(p<0.00 \mathrm{I})$, ranging from less than $2 \%$ for whooping cough to $49 \%$ for otitis media.

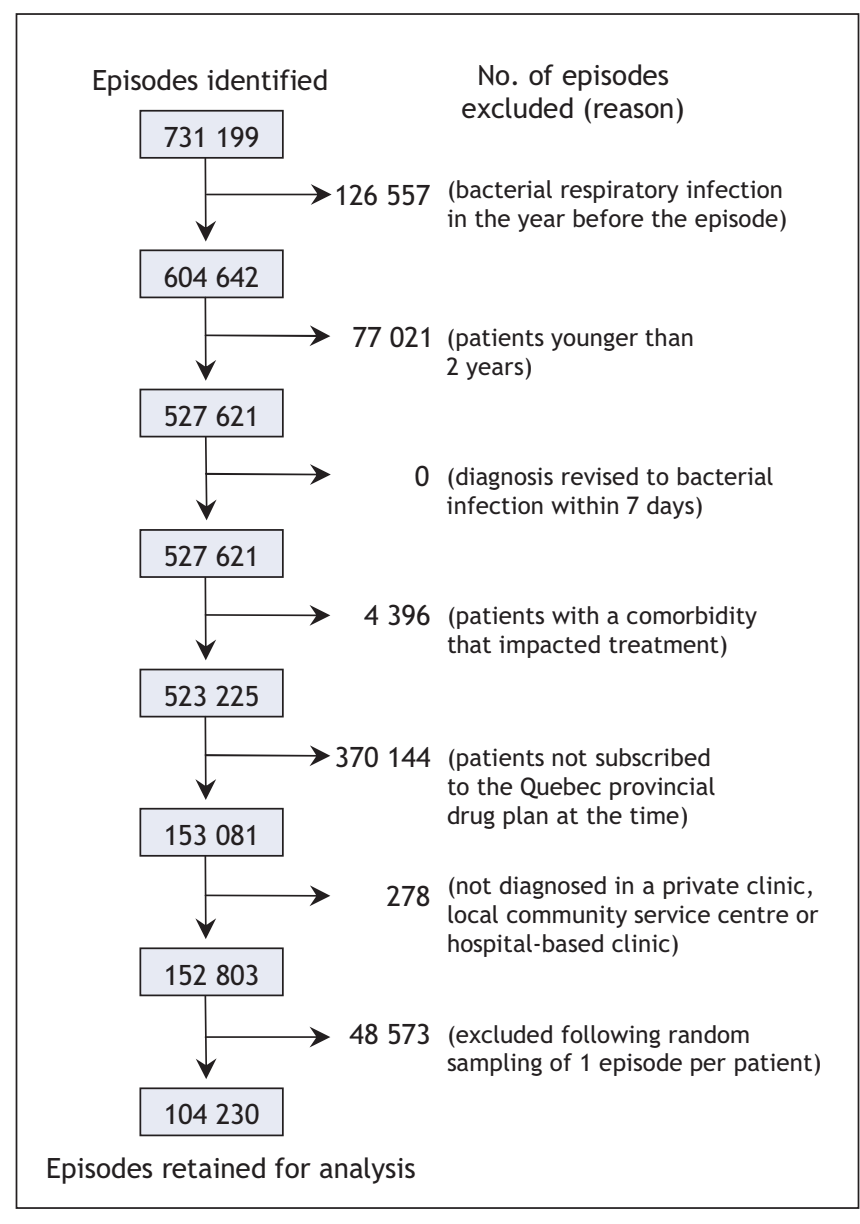

Figure 1: Eligible episodes of viral respiratory infections and reasons for exclusion.
International medical graduates, compared with graduates from the University of Montréal, were more likely to prescribe antibiotics for a viral respiratory infection (adjusted RR I.78, 95\% confidence interval [CI] I.30-2.44) (Figure 3, Appendix 3 , available online at www.cmaj.ca/cgi/content/full/177 /8/877/DC2). Licensing examination scores were not associated with either measure of inappropriate antibiotic prescribing (Figure 3, Figure 4). Physicians who did not write the Medical Council of Canada Qualifying Examination were not included in the regression analyses presented in Figure 3 and Figure 4. Inappropriate antibiotic prescribing for viral respiratory infections increased by $4 \%$ with each year in practice. Inappropriate prescribing for bacterial infections increased by II\% with each year in practice. Physicians who had higher practice volumes were more likely than those with lower practice volumes to inappropriately prescribe antibiotics.

\section{Interpretation}

We found that physicians who had been in practice longer, who were international medical graduates and who had

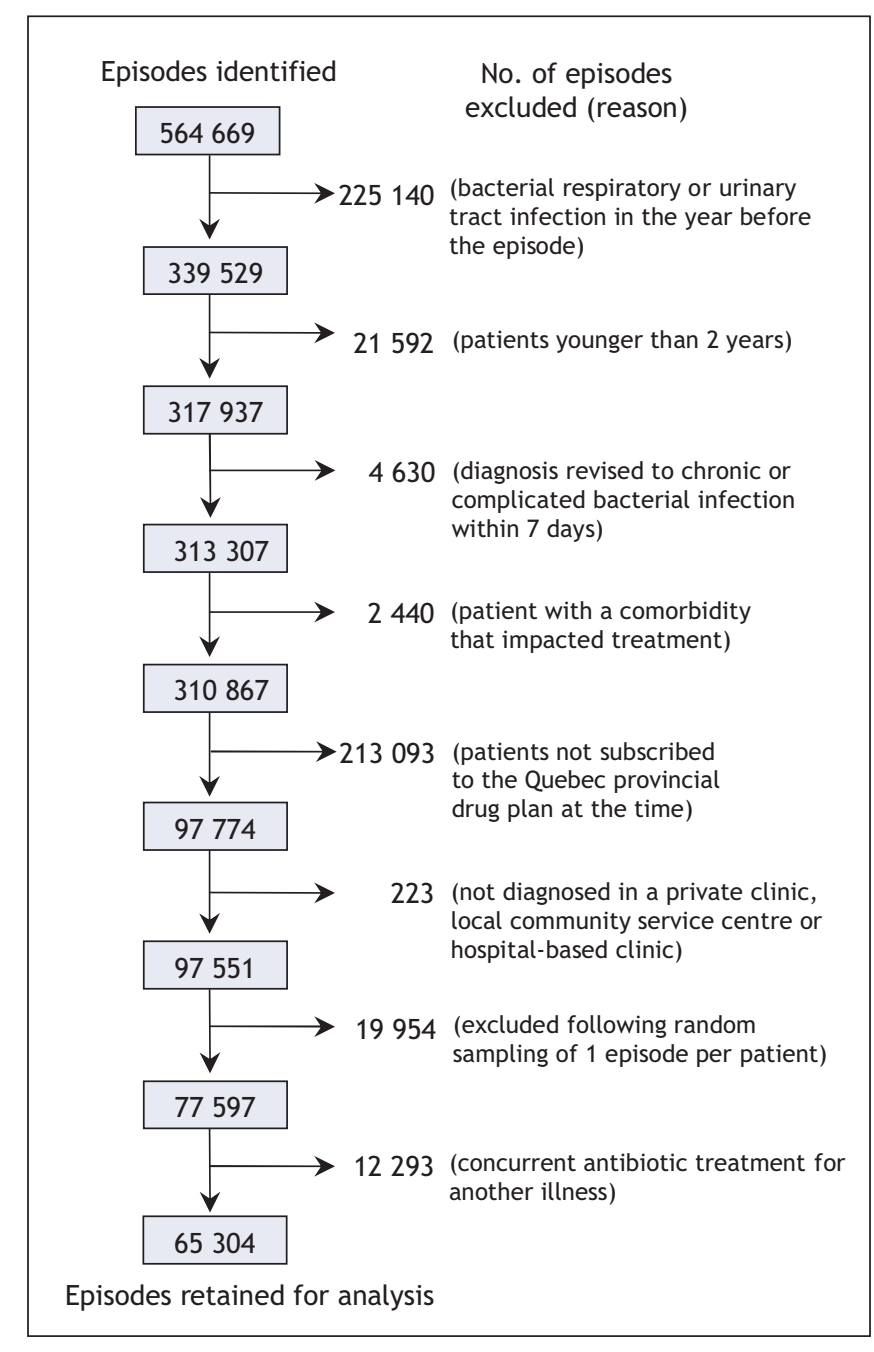

Figure 2: Eligible episodes of bacterial respiratory and urinary tract infections and reasons for exclusion. 
high-volume practices were more likely to prescribe antibiotics inappropriately.

Consistent with previous findings ${ }^{12,13}$ we found that international medical graduates were more likely than University of Montreal graduates to prescribe antibiotics for viral respiratory infections. We adjusted for physician knowledge; thus, it is unlikely that this difference is because of differences in physician knowledge. Rather, training environment may be an important contributor. International medical graduates may continue to prescribe antibiotics in accordance with cultural expectations or with the probability of bacterial infection in their country of training.

Previous studies have shown that the scores obtained on licensure and certification examinations predict drug prescribing, ${ }^{27}$ preventive practices, ${ }^{28}$ chronic disease management outcomes ${ }^{28}$ and scores on subsequent recertification examinations. ${ }^{29}$ Although experience and professional development activities influence physician practice, one of the most important determinants of knowledge on a recertification examination is the score achieved on examinations taken before entry into practice. ${ }^{29}$ Our study found no association between scores on licensure examinations and inappropriate antibiotic prescribing. Possible explanations for our finding may include the following: licensure examinations may not fully test physicians' knowledge of infectious diseases and antibiotics; physicians may acquire knowledge about infectious diseases and antibiotics after graduation; and knowledge may not be the most important determinant of inappropriate antibiotic prescribing.
Using a longitudinal study design to observe withinphysician variation over time, we found that inappropriate antibiotic prescribing increased with time in practice. Qualitative research suggests that, over time, physicians tend to "soften" to patients' demands for antibiotics and that they engage less frequently in patient education to reduce their short-term workload. ${ }^{16}$ This may explain the increase in antibiotic prescribing for viral infections over time; however, increases in the inappropriate prescribing for bacterial infections over time suggests that other mechanisms, such as pharmaceutical detailing, may be responsible.

In our study, physicians with high-volume practices were more likely than physicians with low-volume practices to prescribe antibiotics inappropriately. A similar association has also been observed among Spanish ${ }^{19}$ and Italian ${ }^{20}$ physicians. Practice volume is a complex measure that may reflect interaction with patients and a lack of time for patient education, as well as practice style and patient selection. Practice volume is probably driven by fee-for-service remuneration. A Norwegian study found that physicians in a fee-for-service system were less compliant with antibiotic prescribing guidelines. ${ }^{30}$ The effect of remuneration systems on antibiotic prescribing is important to investigate, because several jurisdictions in North America are changing the type of renumeration for primary care physicians.

Our study has several limitations. Misclassification of infection diagnoses may have occurred, because diagnostic information on physician billing claims is not collected for the purpose of ascertaining treatment indications. Physician

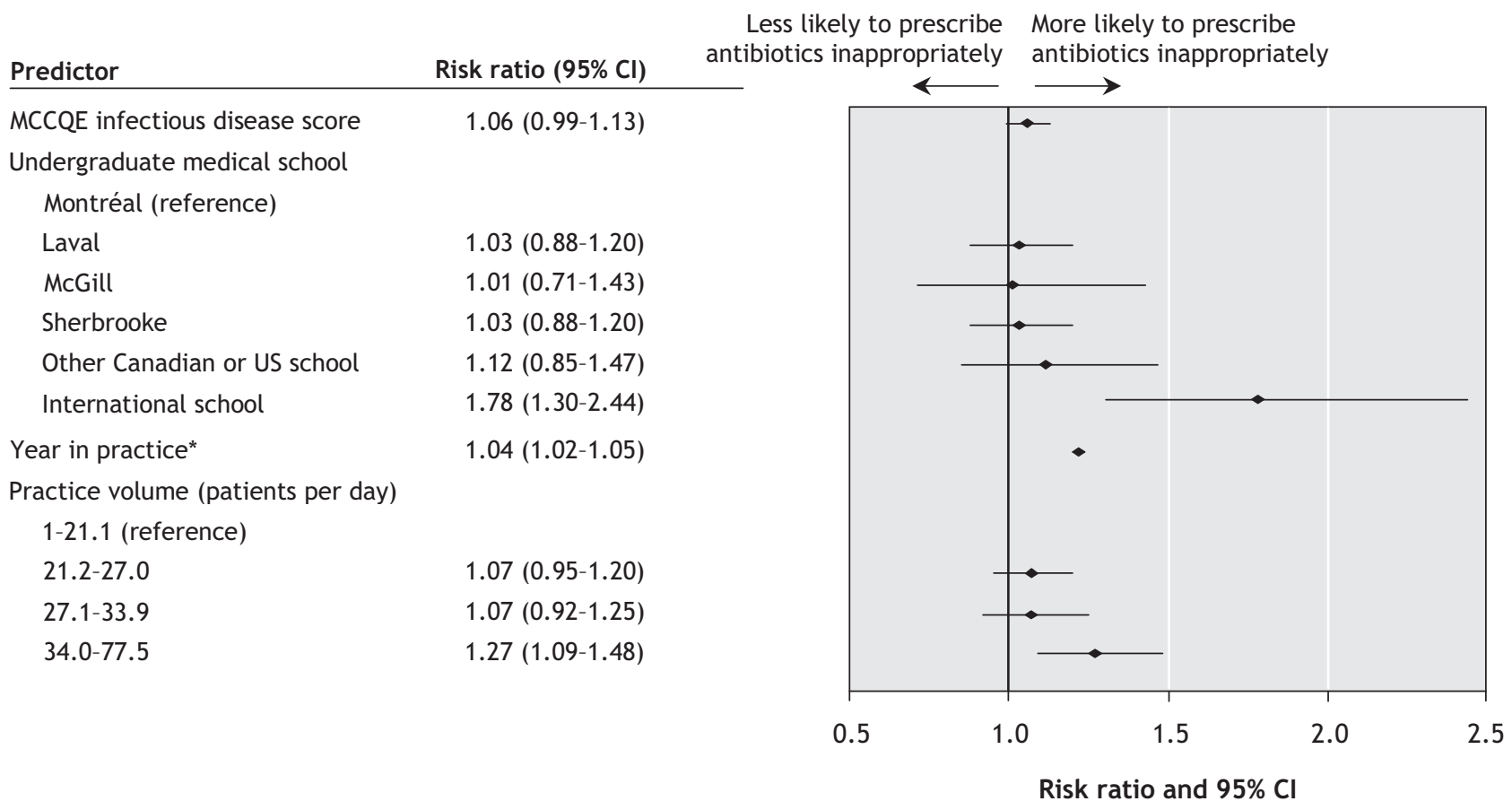

Figure 3: Forest plot of the predictors of inappropriate antibiotic prescribing for likely viral respiratory infections diagnosed by 726 primary care physicians. ${ }^{*}$ The plot shows the effect of 5 years in practice. Note: $\mathrm{Cl}=$ confidence interval, $\mathrm{MCCQE}=\mathrm{Medical}$ Council of Canada Qualifying Examination. 


\begin{tabular}{lc} 
Predictor & Risk ratio $(95 \% \mathrm{Cl})$ \\
\hline $\begin{array}{l}\text { MCCQE infectious disease score } \\
\text { Undergraduate medical school }\end{array}$ & $1.00(1.00-1.00)$ \\
$\quad$ Montréal (reference) & \\
Laval & $1.12(0.99-1.28)$ \\
McGill & $0.74(0.60-0.92)$ \\
Sherbrooke & $1.06(0.92-1.23)$ \\
Other Canadian or US school & $0.79(0.61-1.01)$ \\
International school & $0.87(0.68-1.09)$ \\
Year in practice* & $1.11(1.09-1.13)$ \\
Practice volume (patients per day) & \\
1-21.1 (reference) & \\
$21.2-27.0$ & $1.07(0.96-1.19)$ \\
$27.1-33.9$ & $1.17(1.03-1.32)$ \\
$34.0-77.5$ & $1.20(1.06-1.32)$
\end{tabular}

Less likely to prescribe More likely to prescribe antibiotics inappropriately antibiotics inappropriately

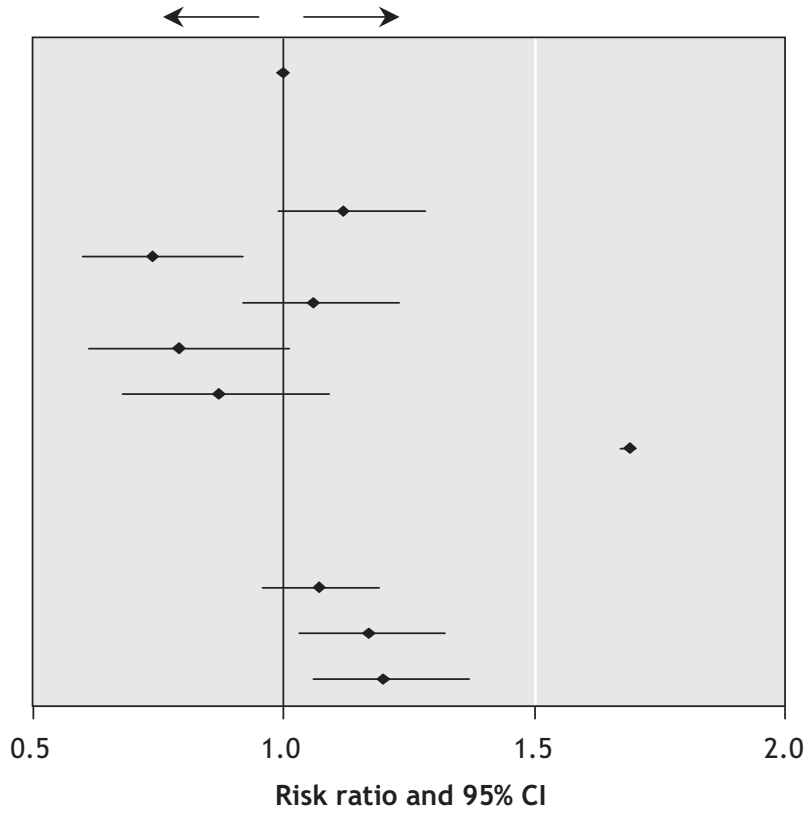

Figure 4: Forest plot of the predictors of inappropriate antibiotic prescribing of second-and third-line antibiotics as first-line treatment of bacterial infections diagnosed by 726 primary care physicians. ${ }^{*}$ The plot shows the effect of 5 years in practice. $\mathrm{Note}$ : $\mathrm{Cl}=$ confidence interval, MCCQE = Medical Council of Canada Qualifying Examination.

knowledge was not assessed at the time of prescribing; therefore, random misclassification of knowledge may underestimate the relation between knowledge and inappropriate antibiotic prescribing. We cannot determine whether such factors as local antibiotic resistance may have affected the physican's choice of a second- or third-line antibiotic. Practice volume is, at best, a proxy measure for lack of time for patient education because we were not able to determine whether education was provided to patients by other means (e.g., office nurses).

We expect that our findings are generalizable to other jurisdictions in North America because accreditation standards are the same or equivalent for all medical schools across Canada and the United States. We used the Quebec prescriptions claims database, ${ }^{31}$ which has been previously validated, to ascertain antibiotic prescribing. This outcome measure is more accurate than physician self-reporting, which has been shown to underreport actual antibiotic prescribing. ${ }^{32}$

Our study suggests that interventions to reduce inappropriate antibiotic prescribing should target international medical graduates, physicians who have been in practice longer and physicians with high-volume practices. Developing effective interventions to reduce inappropriate antibiotic prescribing will require a clear understanding of how these predictors influence antibiotic prescribing. Primary-care reform, new immigration policies for international medical graduates and mandatory recertification may modify the effect of the predictors identified in our study; however, the impact of such policies on antibiotic prescribing should be investigated.
This article has been peer reviewed.

Competing interests: None declared.

Contributors: Genevieve Cadieux defined the exposures and outcomes, developed the methods, performed the data analysis and was the primary author of the manuscript. Robyn Tamblyn acquired the data, assisted in the definition of exposures and outcomes and development of the methods. Robyn Tamblyn also helped draft and revise the manuscript. Michael Libman assisted in the definition of exposures and outcomes, helped develop the methods, and provided useful comments on the manuscript. Dale Dauphinee enabled data acquisition, took part in the development of the methods, and provided useful comments on the manuscript. All of the authors approved the final version submitted for publication.

Acknowledgements: This study was funded by the Canadian Institutes for Health Research.

\section{REFERENCES}

I. Gonzales R, Malone DC, Maselli JH, et al. Excessive antibiotic use for acute respiratory infections in the United States. Clin Infect Dis 2001;33:757-62.

2. Wang EE, Einarson TR, Kellner JD, et al. Antibiotic prescribing for Canadian preschool children: evidence of overprescribing for viral respiratory infections. Clin Infect Dis I999;29:155-60.

3. Stille CJ, Andrade SE, Huang SS, et al. Increased use of second-generation macrolide antibiotics for children in 9 health plans in the United States. Pediatrics 2004;II4:I206-II.

4. Steinman MA, Landefeld CS, Gonzales R. Predictors of broad-spectrum antibiotic prescribing for acute respiratory tract infections in adult primary care. JAMA 2003; 289:719-25.

5. Austin DJ, Kristinsson KG, Anderson RM. The relationship between the volume of antimicrobial consumption in human communities and the frequency of resistance. Proc Natl Acad Sci U S A I999;96:1152-6.

6. Seppala H, Klaukka T, Vuopio-Varkila J, et al. The effect of changes in the consumption of macrolide antibiotics on erythromycin resistance in group A streptococci in Finland. Finnish Study Group for Antimicrobial Resistance. N Engl J Med I997;337:44I-6. 
7. Classen DC, Pestotnik SL, Evans RS, et al. Computerized surveillance of adverse drug events in hospital patients. JAMA I99I;266:2847-5I.

8. Little P, Gould C, Williamson I, et al. Reattendance and complications in a randomized trial of prescribing strategies for sore throat: the medicalising effect of prescribing antibiotics. BMJ I997;315:350-2.

9. Majeed A, Moser K. Age- and sex-specific antibiotic prescribing patterns in general practice in England and Wales in 1996. Br J Gen Pract 1999;49:735-6.

Io. Murray S, Del Mar C, O'Rourke P. Predictors of an antibiotic prescription by GPs for respiratory tract infections: a pilot. Fam Pract 2000;17:386-8.

II. Ben David MF, Klass DJ, Boulet J, et al. The performance of foreign medical graduates on the National Board of Medical Examiners (NBME) standardized patient examination prototype: a collaborative study of the NBME and the educational Commission for Foreign Medical Graduates (ECFMG). Med Educ I999;33:439-46.

I2. Gill PS, Roalfe A. Antibiotic prescribing by single handed general practitioners: secondary analysis of data. JClin Pharm Ther 200I;26:195-9.

13. Kozyrskyj AL, Dahl ME, Chateau DG, et al. Evidence-based prescribing of antibiotics for children: role of socioeconomic status and physician characteristics. CMAJ 2004;I7I:139-45.

I4. Stone S, Gonzales R, Maselli J, et al. Antibiotic prescribing for patients with colds, upper respiratory tract infections, and bronchitis: a national study of hospitalbased emergency departments. Ann Emerg Med 2000;36:320-7.

15. Steffensen FH, Schonheyder HC, Sorensen HT. High prescribers of antibiotics among general practitioners-relation to prescribing habits of other drugs and use of microbiological diagnostics. Scand I Infect Dis I997;29:409-I3.

I6. Butler CC, Rollnick S, Pill R, et al. Understanding the culture of prescribing: qualitative study of general practitioners' and patients' perceptions of antibiotics for sore throats. BMJ I998;317:637-42.

7. Garcia-Rey C, Aguilar L, Baquero F, et al. Importance of local variations in antibiotic consumption and geographical differences of erythromycin and penicillin resistance in Streptococcus pneumoniae. J Clin Microbiol 2002;40:159-64.

18. Bronzwaer SL, Cars O, Buchholz U, et al. A European study on the relationship between antimicrobial use and antimicrobial resistance. Emerg Infect Dis 2002;8 278-82.

I9. Figueiras A, Caamano F, Gestal-Otero JJ. Influence of physician's education, drug information and medical-care settings on the quality of drugs prescribed. Eur Clin Pharmacol 2000;56:747-53.

20. Mazzaglia G, Caputi AP, Rossi A, et al. Exploring patient- and doctor-related vari- ables associated with antibiotic prescribing for respiratory infections in primary care. Eur J Clin Pharmacol 2003;59:65I-7.

2I. Gonzales R, Bartlett JC, Besser RE, et al. Principles of appropriate antibiotic use for treatment of acute respiratory tract infections in adults: background, specific aims, and methods. Ann Intern Med 2001;134:479-86.

22. Fahey T, Stocks N, Thomas T. Systematic review of the treatment of upper respiratory tract infection. Arch Dis Child I998;79:225-30.

23. Wilchesky M, Tamblyn RM, Huang A. Validation of diagnostic codes within medical services claims. JClin Epidemiol 2004;57:I3I-4I.

24. Ontario Anti-Infective Review Panel. Anti-infective guidelines for community acquired infections 1994/95. Toronto: Queen's Printer for Ontario; 1994.

25. Gonzales R, Sande MA. Uncomplicated acute bronchitis. Ann Intern Med 2000 I33:98I-9I.

26. Mustard CA, Derksen S, Berthelot JM, et al. Assessing ecologic proxies for household income: a comparison of household and neighborhood level income measures in the study of population health status. Health Place 1999;5:157-71.

27. Tamblyn R, McLeod P, Hanley JA, et al. Physician and practice characteristics associated with the early utilization of new prescription drugs. Med Care 2003;4I:895-908.

28. Tamblyn R, Abrahamowicz M, Dauphinee WD, et al. Association between licensure examination scores and practice in primary care. JAMA 2002;288:30I9-26.

29. Ramsey PG, Carline JD, Inui TS, et al. Changes over time in the knowledge base of practicing internists. JAMA I991;266:1103-7.

30. Straand J, Rokstad KS, Sandvik H. Prescribing systemic antibiotics in general practice- a report from the More and Romsdal Prescription Study. Scand J Prim Health Care 1998; I6:12I-7.

3I. Tamblyn R, Lavoie G, Petrella L, et al. The use of prescription claims databases in pharmacoepidemiological research: the accuracy and comprehensiveness of the prescription claims database in Quebec. J Clin Epidemiol I995;48:999-1009.

32. Mangione-Smith R, Elliott MN, McDonald L, et al. An observational study of antibiotic prescribing behavior and the Hawthorne effect. Health Serv Res 2002;37:1603-23.

Correspondence to: Ms. Genevieve Cadieux, Department of

Epidemiology and Biostatistics, McGill University, II4o Pine Ave. W, Montréal QC H3A IA3; genevieve.cadieux@mail.mcgill.ca 